\title{
The characteristics of heat inside a parked car as energy source for thermoelectric generators
}

\author{
Aris Sunawar ${ }^{1} \cdot$ Iwa Garniwa $^{1,2} \cdot$ Chairul Hudaya $^{1,2}$ (i) \\ Received: 8 February 2019 / Accepted: 17 June 2019 / Published online: 1 July 2019 \\ (c) The Author(s) 2019
}

\begin{abstract}
Under a condition of sunlight exposure, the temperature of a parked car's cabin will increase gradually. Compared to the ambient temperature, the inside and outside temperature will be different, which will be favourable for thermoelectric generators. This study investigated the temperature distribution pattern of a car parked in the direct sun using real and model cars. Performing different scenarios, we found that the car model equipped with a fan and a dimmer was the suitable approach to the real car model. Compared to the ambient temperature, results for both the real car and the model car indicated that heat rose drastically inside the car cabin. The calculation using the thermoelectric generator eTEG HV37 considerably could generate up to $6.9 \mathrm{~mW}$ per module. Therefore, by having a thermoelectric generator installed on an area of $1 \mathrm{~m}^{2}$ of the car roof, $280 \mathrm{~W}$ power could be generated.
\end{abstract}

Keywords Parked car $\cdot$ Thermoelectric generator $\cdot$ Car temperature $\cdot$ Heat distribution

\section{List of symbols}

$Z \quad$ Figure of merit for power a device can generate $\mathrm{K}^{-1}$

$P \quad$ Power a TEG generates (W)

$V \quad$ Voltage a TEG generates (V)

I Current a TEG generates (A)

$\rho_{\mathrm{C}} \quad$ Electrical conductivity for cold materials $\mu \Omega \mathrm{m}$ (12.6 $\mu \Omega \mathrm{m}$ for $p$-type antimony telluride)

$\rho_{\mathrm{H}} \quad$ Electrical conductivity for hot materials $\mu \Omega \mathrm{m}$ (12.6 $\mu \Omega \mathrm{m}$ for $n$-type bismuth telluride)

$K_{\mathrm{C}} \quad$ Thermal conductivity for cold materials $\mathrm{W} / \mathrm{mK}$ (1.65 W/mK for $p$-type antimony telluride)

$K_{\mathrm{H}} \quad$ Thermal conductivity for hot materials W/mK (1.8 W/mK for $n$-type bismuth telluride)

$S_{\mathrm{C}} \quad$ Seebeck coefficient for cold materials $\mu \mathrm{V} / \mathrm{K}$ (185 $\mu \mathrm{v} / \mathrm{K}$ for $p$-type antimony telluride)

$S_{\mathrm{H}} \quad$ Seebeck coefficient for hot materials $\mu \mathrm{v} / \mathrm{K}$ ( $-228 \mu \mathrm{V} / \mathrm{K}$ for $n$-type bismuth telluride)

$T_{\mathrm{C}} \quad$ Temperature of the cold side of a TEC (K)

Chairul Hudaya

c.hudaya@eng.ui.ac.id

1 Department of Electrical Engineering, Faculty of Engineering Universitas Indonesia, Kampus Baru UI, Depok 16424, Indonesia

2 Energy System Engineering, Faculty of Engineering Universitas Indonesia, Kampus Baru UI, Depok 16424, Indonesia
$T_{\mathrm{H}} \quad$ Temperature of the hot side of a TEC (K)

$\mathrm{R}_{p} \quad$ Thermal resistance of $p$-type antimony telluride

$\mathrm{R}_{n} \quad$ Thermal resistance of $n$-type bismuth telluride

$R_{\mathrm{L}} \quad$ Load connected to a TEG

\section{Introduction}

Heat from direct sunlight entering into the cabin of a parked car causes not only discomfort, but also a variety of new problems, from inducing damage to the materials inside the cabin to distributing toxic chemicals. This phenomenon is attributed to the greenhouse effect inside the cabin of parked car, where solar irradiation is trapped in the cabin, leading to accumulated heat. To accelerate heat dissipation, one will likely turn on the car cooling system at the maximum position that will certainly increase fuel consumption.

Many researchers have devoted much attention to overcome the problems such as using photovoltaic-powered ventilation [1], using a solar reflective cover [2], obtaining power from photovoltaics for cooling system activation [3], and using a thermoelectric-based cooler [4]. The latest approach is of interest, as it offers a number of advantages, which include no moving part, no Freon refrigerant, no noise, no vibration, a very small size, long life, and the precise temperature control ability [5]. 
Thermoelectric technology works according to the Thomson effects, i.e., either by directly converting heat energy into electricity (thermoelectric generator/TEG) or, vice versa, by converting electricity to produce cold or heat (thermoelectric cooler/TEC). To generate electricity, simply place thermoelectric materials in such a way as to connect a source of heat and cold. From the device arrays, power will be generated, whose capacity will depend on the type of material used [6].

Many attempts have been devoted to use thermoelectrics for cars, whether as a cooler or as a generator. Attar et al. designed and tested the optimum design of an automotive thermoelectric air conditioner and the experiment result has provided an uncomplicated method to study the optimum design at given inputs [7]. Choi et al. developed a temperature-controlled car-seat system and the design has successfully controlled the cold temperature of a car seat [8]. The energy from the car's waste heat could be harvested using a thermoelectric generator, although a TEG has low temperature limits and low efficiency. The research undertaken by Weng et al. run a simulation of automotive waste heat recovery using thermoelectrics and found out that larger total power was obtained from the downstream exhaust pipe of the car [9]. Orr et al. validated an alternative method to predict thermoelectric generator performance and the result has been a combined waste heat recovery TEG with heat pipes to create a completely solid state and passive system [10]. He et al. evaluated the peak power and the optimal design for the dimensions of an exhaust heat exchanger and found out that flow velocity and TEG module area are two key parameters for TEG system optimization [11]. Then, Muralidhar et al. analyzed energy recovery modeling, where TEGs could save on fuel of a hybrid electric heavy duty vehicle [12].

When parked outside in an unshaded area, heat trapped inside a car can make passengers and drivers feel discomfort when entering the car. It is true that many studies have shown that the level of comfort varies between people. However, talking about vehicles, there are certain limits which, if they are too high, they may cause a sense of stress. Danca et al. stated that thermal comfort leads to a safer trip, because it reduces the driver's stress [13]. Research by Singh et al. showed that a uniform temperature inside the cabin of a parked car can be maintained using a particular vent angle, unfortunately not every car has a dynamic air vent [14]. Lahimer et al. used solar reflective cover to maintain the temperature inside the car close to the ambient one, but it still took time to reach a comfortable temperature [2].

In an area with a sunny and tropical weather such as Indonesia, the temperature inside the cabin rises so high. Results of the study by Othoman et al. [15] have shown that the temperature inside the cabin exceeds $60 \%$ of the ambient temperature and this heat is too high that can lead to the danger of heat strokes. However, the study on the heat inside a parked car as a heat source for thermoelectric generator system is still rare, in which researchers such as Weng et al. [9-11] only used heat from engine waste heat which needed the engine to be running. Meanwhile, the heat inside the cabin is not the same in value, and it has a pattern, where the heat of the surface on the top of the car is higher than that of the lower surface, allowing the difference in temperature to be used to generate power by means of a thermoelectric generator.

In this study, we investigated the optimum locations of hot spots inside the car cabin, where thermoelectric generators were located later. Furthermore, we simulated the power that could potentially be generated through TEG installation. Some parameters, including a variety of different sensor locations, shielding utilization, and heat source variations, were observed. We found that the difference in temperature inside and outside the car could reach approximately $25^{\circ} \mathrm{C}$. From these conditions, the power that could be generated using thermoelectric generators could reach up to $6 \mathrm{~mW}$, making it feasible to be implemented in cars.

\section{The fundamentals of TEGs}

\section{The structure of TEGs}

Thermoelectric generators are a type of energy generator developed based on the Seebeck effect. Briefly, if two metallic materials, generally semiconductors, are connected in environments with a different temperature, an electric current and/or electromotive force will occur. There are two types of thermoelectric elements, the first one is thermoelectric generators (TEGs) which generate power from a heat source and the second one is the thermoelectric coolers (TECs), commonly used for water dispenser coolers.

\section{Characteristics of thermoelectric generators}

Thermoelectric devices generally use semiconductor materials or, in other words, solid-state technology. The structural diagram of a thermoelectric device is shown in Fig. 1. It displays a thermoelectric structure consisting of $p$-type and $n$-type element arrangements. Briefly, heat is transferred from the hot side to the cold side through the thermoelectric material made of antimony telluride for the $p$-type and bismuth telluride for the $n$ type. This phenomenon will lead to power generation when heat transfer passes through the thermoelectric material indicated by the generated voltage in the terminal. The magnitude of voltage is certainly proportional to the gradient of the temperature.

Once the surface of thermoelectric materials is heated in one side and cooled in the other side, electrons in the hot side of the surface will actively move to the other side. 
Fig. 1 Work principals of thermoelectric devices: a thermoelectric cooler and $\mathbf{b}$ thermoelectric generator
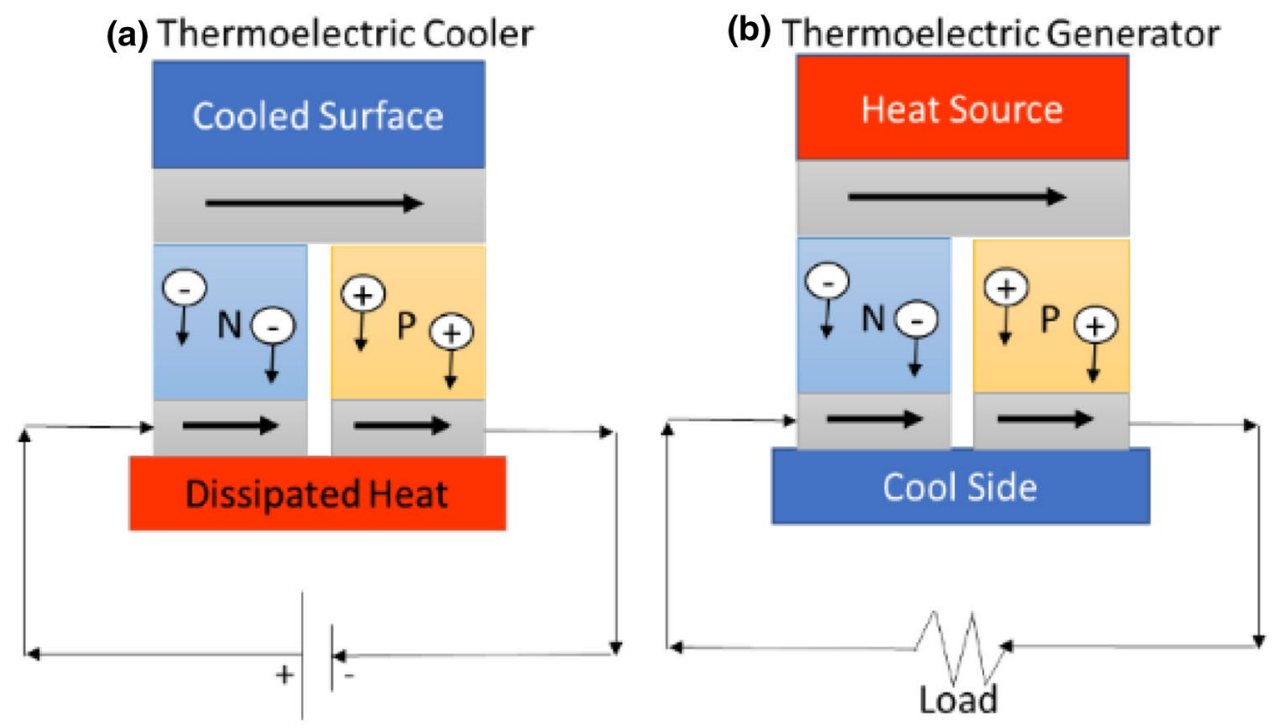

Moreover, it will have a higher flow velocity compared to the cold side of the surface. The higher speed of electrons in the hot side surface will make them faster to diffuse to the cold side. This will contribute to the electric field to appear on the metal junction of the materials.

Potential power generation from a single thermoelectric varies depending on its size, construction, and the difference in the temperature received. The greater the difference in the temperature received is, the greater the current produced is. Thermoelectric devices can be used directly as a power supply to produce electricity. Each thermoelectric device can produce an average voltage of 1-5 VDC, depending on the variation of heating and cooling systems. In general, thermoelectric devices will continue to generate electricity if there is a temperature difference between the two sides of the surface.

\section{The developed TEG system}

This study is aimed to determine heat distribution inside a parked car under a condition of direct sun exposure in a region with a tropical climate. Heat energy is one of energy sources that can be converted into other forms of energy such as motion energy or electrical energy. It is well known that the process of heat changing into electricity requires energy conversion devices leading to loss of power. Using a thermoelectric module, heat energy can be converted into electrical energy due to a temperature difference between both sides of thermoelectric devices.

The experimental setup consisted of a model car equipped with a $500 \mathrm{~W}$ heater lamp positioned above the box, a dimmer $(500 \mathrm{k} \Omega)$ to control the lamp power, a fan $(80 \mathrm{~mm} 12 \mathrm{~V}$ DC) located in one side of the box to supply an air flow inside the box, five points of type-K thermocouple sensors, and a wooden box wrapped in aluminium foil to prevent heat loss in a $0.6 \times 0.5 \times 0.6 \mathrm{~m}^{3}$ size. The thermocouple sensors were used to measure the difference in temperature outside and inside the car in five different spots. The first one was placed on the outside roof of the car (T1), the second one was on the inside roof of the car (T2), the third one was on the cabin above the seat (T3), the fourth one was under the car (T4), and the fifth one was the ambient temperature near the car (T5), as shown in Fig. 2a.

The first setup is described in Fig. 2b, in which this setup consisted only one lamp to heat the car placed $40 \mathrm{~cm}$ above the roof, the second scenario setup is shown in Fig. 2c, added box to contain the heat inside the box, so the heat from the lamp was not mixed with the heat from room, the third setup scenario is shown in Fig. 2d, the box was still the same with Scenario 2, but a dimmer was added in the lamp to reduce the heat inside the box, the fourth setup scenario is shown in Fig. 2e, and the box was still the same with Scenario 2, but a fan was added at one side of the box to circulate the heat inside the box. The last scenario is shown in Fig. 2f, and it was a combination of a dimmer and a fan in the box.

We studied the real car scenario and the model car scenario. The real car and the model car used in this experiment were 2016 Honda HR-V with scale of 18:1, and the color of the car was black. BTM4208SD Lutron Temperature Data logger was used to acquire the temperature data with sampling ability of 1-s intervals. Prior to the measurement, we calibrated the data logger with conventional-but-accurate temperature reading Beamex MC5 Multifunction Calibrator. We found that the data logger had $0.2 \%$ of error measurement. Table 1 describes the detailed scenario models, and the test was carried out by heating for $60 \mathrm{~min}$ to get the temperature rise graph inside the car. Thermal camera (Flir ONE) was used, to get the image of the heat radiation pattern contained in the car surface after heating. Each test lasted for about $60 \mathrm{~min}$ 
Fig. 2 Variation of experimental setup a 5 position of thermocouple test point on a model car, b model car without a box scenario, c model car with a box scenario, $\mathbf{d}$ model car with a box and a dimmer scenario, e model car with a box and a fan scenario, and $\mathbf{f}$ model car with a box, a dimmer and a fan scenario (a)

(b)

h

(f)
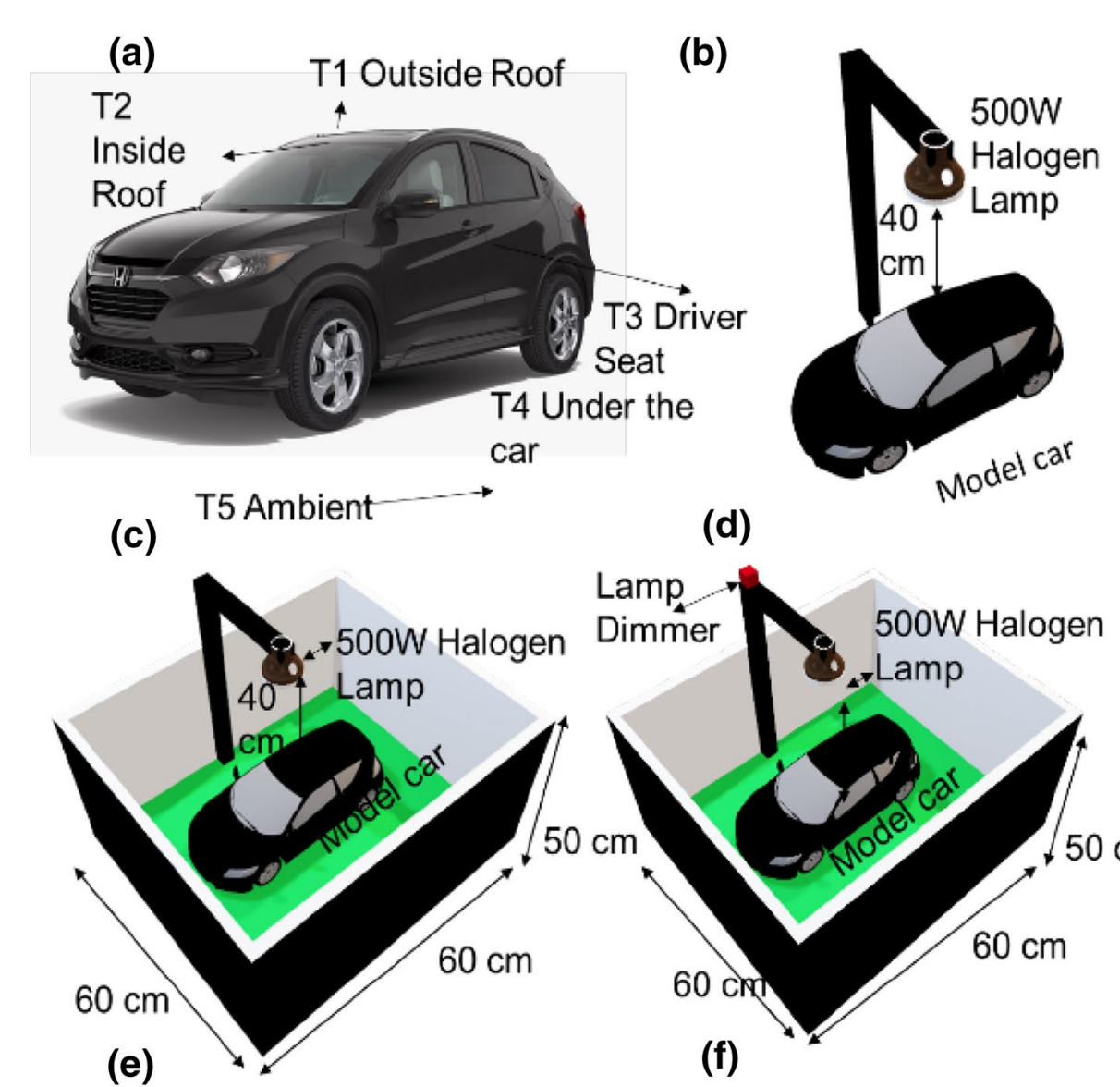

(d)
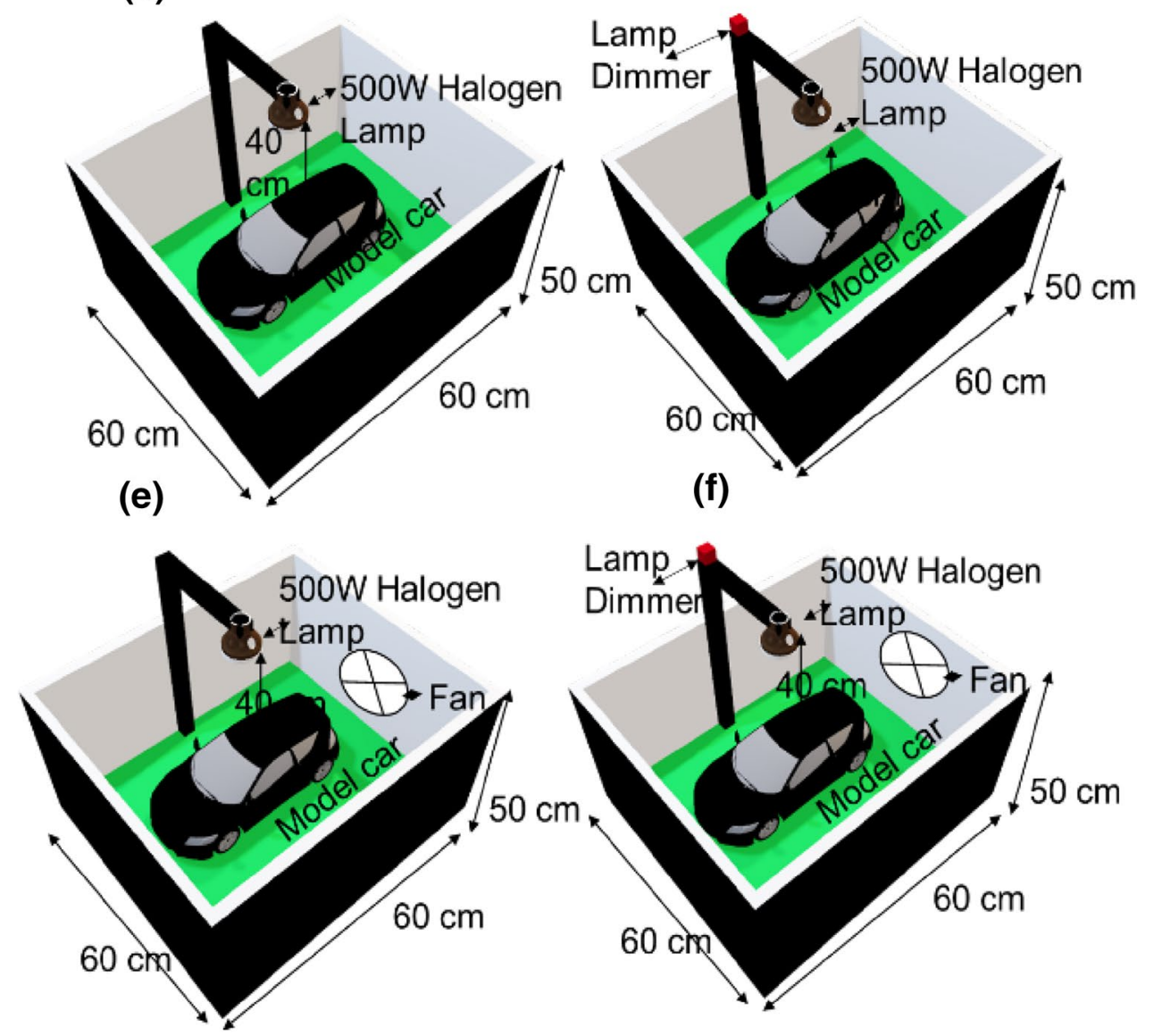

\begin{tabular}{llll}
\hline Scenario Name & Box Set & Dimmer & Fan \\
\hline Model car without a box (Scenario 1) & No & No & No \\
Model car with a box (Scenario 2) & Yes & No & No \\
Model car with a box and a dimmer (Scenario 3) & Yes & Yes & No \\
Model car with a box and a fan (Scenario 4) & Yes & No & Yes \\
Model car with a box, a dimmer, and a fan (Scenario 5) & Yes & Yes & Yes \\
\hline
\end{tabular}

Table 1 Scenario setups using the following formulas [6]:
The figure of merit $(Z)$ and current $(I)$ need to be calculated
To calculate the power of a TEG, first, we calculated the figure of merit and the current it could generate, as follows. 
$Z=\left[\frac{S_{\mathrm{H}}-S_{\mathrm{C}}}{\sqrt{\sqrt{\rho_{\mathrm{H}} K_{\mathrm{H}}}-\sqrt{\rho_{\mathrm{C}} K_{\mathrm{C}}}}}\right]^{2}$

$I=\frac{\left(S_{\mathrm{H}}-S_{\mathrm{C}}\right)\left(T_{\mathrm{H}}-T_{\mathrm{C}}\right)}{R_{p}+R_{n+} R_{\mathrm{L}}}$.

In our experimental scope, we used Nextreme eTEG ${ }^{\mathrm{TM}}$ HV37 Power Generator as a thermoelectric generator, whose specifications are shown in Table 2.

The current rate from the thermoelectric device in Eq. (2) is due to a difference in temperature between the sides of a thermoelectric and can be described using the following equations to calculate the power generated by the thermoelectric [6]:

$P=V \times I$

$P=V \times\left[\frac{\left(S_{\mathrm{H}}-S_{\mathrm{C}}\right)\left(T_{\mathrm{H}}-T_{\mathrm{C}}\right)}{R_{p}+R_{n+} R_{\mathrm{L}}}\right]$.

Using Eq. (4) and by substituting the thermoelectric generator data, the magnitude of power that can be produced by a single eTEG ${ }^{\mathrm{TM}} \mathrm{HV} 37$ thermoelectric module can be estimated by giving a temperature difference $(\Delta \mathrm{T})$ according to the measurement.

\section{Results and discussion}

The first part of this study is to determine the optimum experimental pattern to represent the real car model. Therefore, we analyzed the heat pattern of the model car to find out the maximum temperature in the vehicle cabin and the temperature increase compared to the ambient temperature.

Table 2 Performance specification data of nextreme eTEGTM HV37 power generator

\begin{tabular}{lllll}
\hline Parameter & Unit & \multicolumn{2}{l}{$\Delta T(\mathrm{~K})$} & \\
\cline { 3 - 5 } & & 10 & 50 & 100 \\
\hline \multicolumn{4}{l}{ Typical performance specification } \\
$P_{\text {out }}$ & $\mathrm{mW}$ & 1 & 24 & 90 \\
$V_{\text {out }}$ & Volts & 0.09 & 0.4 & 0.85 \\
$I_{\text {out }}$ & $\mathrm{mA}$ & 12 & 60 & 105 \\
$V_{\mathrm{OC}}$ & Volts & 0.18 & 0.8 & 1.7 \\
$I_{\mathrm{SC}}$ & $\mathrm{mA}$ & 24 & 115 & 210 \\
\hline
\end{tabular}

Performance maximized with matched electrical load
According to Othoman et al. [15], an increase in the car cabin's temperature due to solar heat could reach $60 \%$ higher than the ambient temperature. Other researchers, among others, Horak, Grundstein, Guard, and Al-Kayiem [16-20], also stated that a high temperature rise in the cabin can be harmful for humans and can be dangerous for sensitive objects inside the car. Even if the car is parked for less than $60 \mathrm{~min}$, it is still really dangerous and may take lives of humans or animals inside the car.

\section{The scenario with a real car parked}

The real car used in the test was parked in an open space in the direct sunlight. This experiment was aimed to determine the characteristics of a temperature increase in the actual car cabin compared to the other car model used later.

Based on observation, the heat in the car rose drastically within a 60-min test, as shown in Fig. 3a. The temperature rise outside above the car (T1) tended to fluctuate because of the wind and cloud that changed heat of the sun. The temperature difference between the inside of the car and the ambient temperature was quite high, where the temperature inside the cabin (T2) reached $63^{\circ}$ and it was higher than the ambient temperature (T5) which was stable at $35^{\circ}$.

This experiment showed the same results as Grundstein's experiments [21]. The temperature in the driver seat (T3) also rose up to $45^{\circ}$, and this heat could be dangerous to humans and the other objects inside the car as mentioned by Horak [18]. The temperature under the car (T4) was stable and almost the same as the ambient one (T5). In the 20-min test, the temperature outside dropped, because clouds blocked the sun, but the temperature inside the car remained the same and then decreased following the temperature outside.

\section{Simulation}

\section{Open box (Scenario 1)}

To predict a heat increase inside the car under different conditions, five different scenarios were proposed and are given in Table 1. The first trial was carried out by testing the model car inside a room, but it was undertaken without a divider box, so that the surroundings of the car were an open place.

Observation was performed in the scenario without a box, as shown in Fig. 4a. The results suggested that the heat pattern rose drastically in a 60-min test just like in the real car scenario, where both $\mathrm{T} 1$ and $\mathrm{T} 2$ rose. However, the maximum temperature recorded in $\mathrm{T} 2$ was lower than that one in the real car scenario, which was about $50^{\circ}$. 


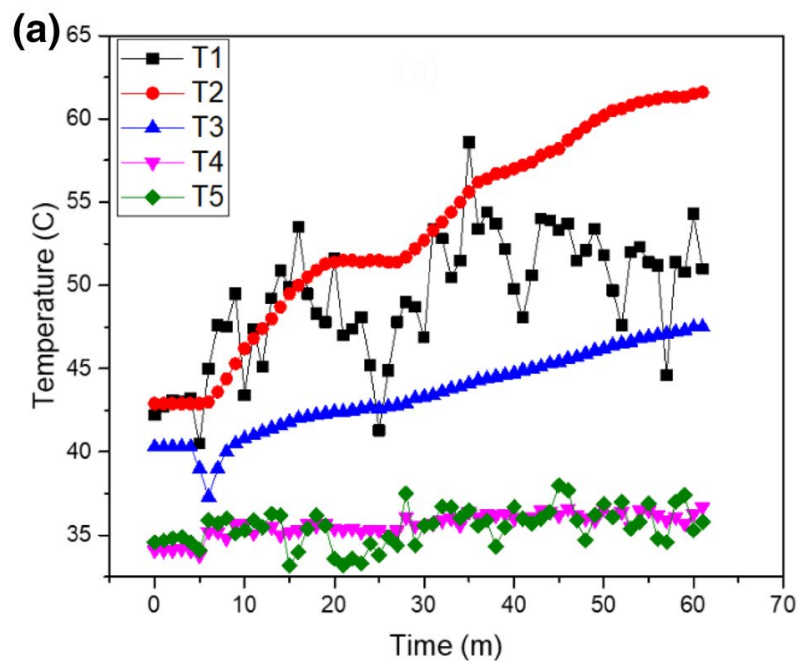

(b)

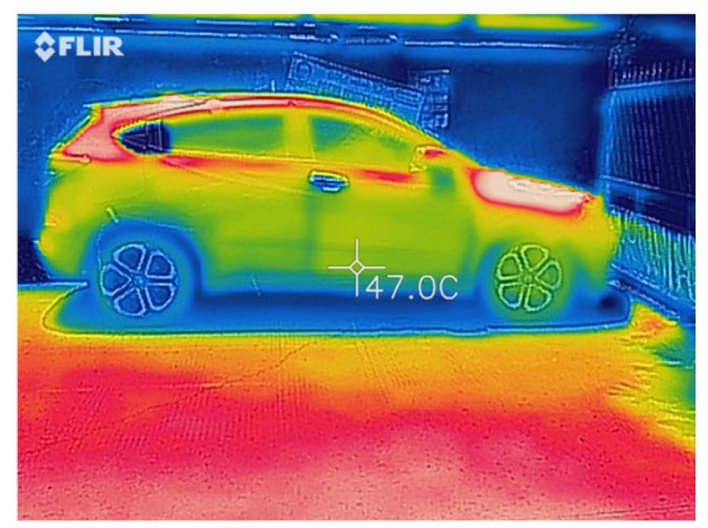

Fig. 3 Real car scenario a graphic of temperature rise, $\mathbf{b}$ heat distribution image

The ambient temperature (T5) was not too high, and this was probably related to the fact that the wind and the airconditioning system in the room affected the thermocouple reading. The difference between the roof temperature $\mathrm{T} 2$ and the ambient temperature T5 was quite high, i.e., more than $20^{\circ}$, but still lower compared to the real car. In addition, the temperature T3 was still lower than the temperature T2, but the temperature $\mathrm{T} 4$ tended to rise.

\section{Closed box (Scenario 2)}

We designed a box made of wood coated with aluminium foil on the inside to keep the temperature in the box constant and unaffected by changes in the room temperature outside the box. The experiment was carried out in the same which was as the trial without a box, i.e., by heating the model car for $60 \mathrm{~min}$ using the same heater.

The configuration of the closed box in Scenario 2 showed a heat rise higher than that one in the real car scenario, as

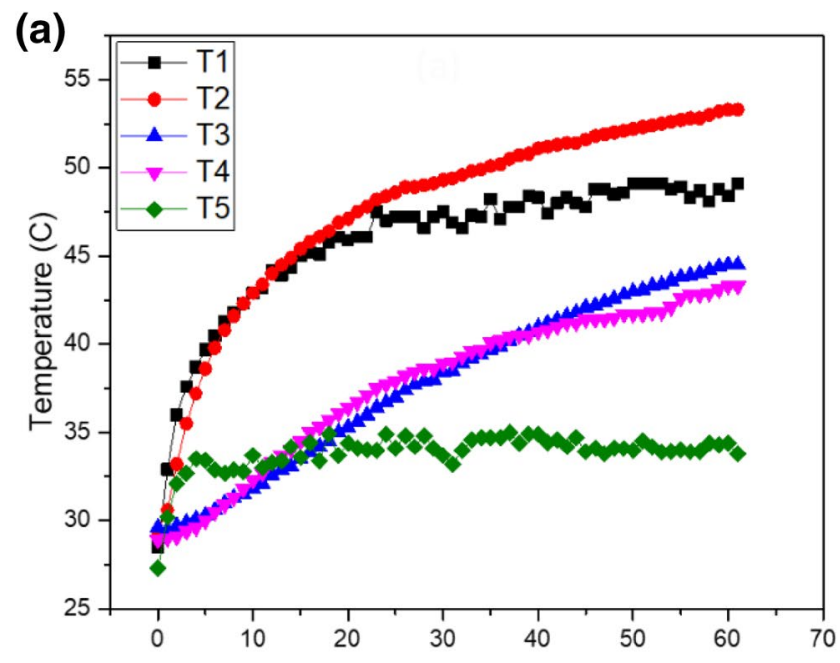

(b)

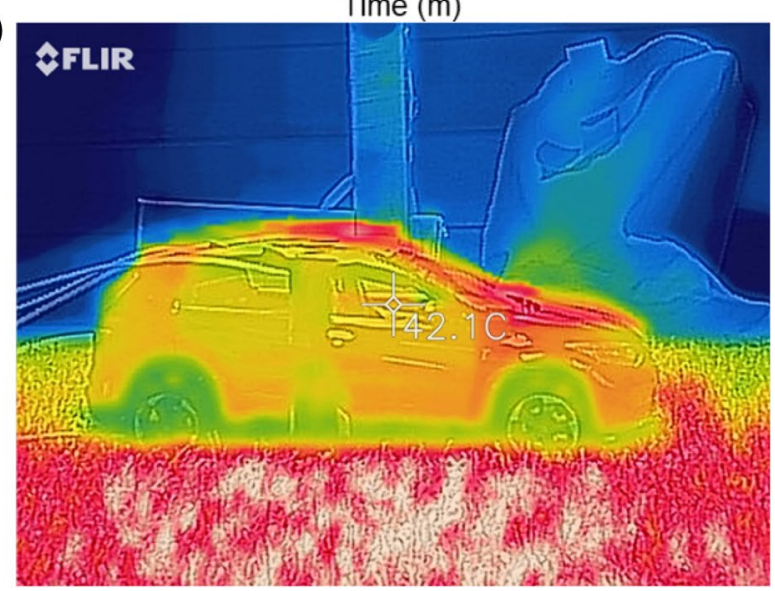

Fig. 4 Open box (Scenario 1) a graphics of temperature rise in a model car, $\mathbf{b}$ heat distribution image of a model car

shown in Fig. 5a. T2 could reach $65^{\circ}$, which was higher than the resulting temperature rise in the real car scenario, but the heat outside the ambient temperature (T5) also rose dramatically, reaching almost $45^{\circ}$.

Such a rise could not be controlled, probably as the heat was trapped inside the box and there was no wind flowing inside the box. The difference between temperatures inside and outside was almost the same as the one in the real car scenario, which was $25^{\circ}$. However, the temperature in the seat (T3) also rose drastically, which did not happen in the real car scenario, where it was almost the same as T2. Moreover, the temperature under the car (T4) was high but almost the same as the ambient temperature (T5).

\section{Closed box with a dimmer (Scenario 3)}

Furthermore, another model was built based on a reduction in the amount of heat supplied into the car model, i.e., by 
adjusting the magnitude of the heat of the lamp using a dimmer. From the maximum power of the lamp, power was set, so that only half the heat power came out of the lamp. The experiment was also carried out for $60 \mathrm{~min}$ without changing the other parameters.

These parameters were done to analyze the accuracy of the heat change inside the car. The results from the model car can be compared with the experiment starting with the real car scenario.

Under a dimmer condition, the heat flow reduced drastically. According to Fig. 6a, the maximum temperature inside the cabin (T2) was only $44^{\circ}$, which was lower that in the real car scenario, and the ambient temperature went down to $34^{\circ}$. The heat rise changed, because the dimmer system reduced the heat source power. The temperature difference between $\mathrm{T} 2$ and $\mathrm{T} 5$ was lower than the real car, which was around $10^{\circ}$. However, the temperatures in the seat (T3) and above the car (T4) also rose drastically, which were not close to those in the real car scenario.

\section{Closed box with a fan (Scenario 4)}

To control the wind flow, the system was implemented using a fan. In the implementation of the developed test scenario, the fan was expected to help simulate changes in wind movements around the car model. Because in real conditions, there is a flow of wind around the car, although in this research, the wind strength and direction were not calculated.

According to Fig. 7a, the fan converged change in the flow of wind around the car, because all sensors outside the car (T1) and (T5) underwent fluctuations. In addition, readings shown by the $\mathrm{T} 1$ and $\mathrm{T} 5$ sensors changed, because the wind rotating in the box helped reducing the temperature that entered the car.

Although the temperatures T2 and T3 were still high, such a decrease indicated that the effect of the wind around the car made T1 fluctuating which resulted in maximum temperatures approaching the testing without a box. The temperature difference between $\mathrm{T} 2$ and $\mathrm{T} 5$ could reach $25^{\circ} \mathrm{s}$, which was close to real car difference.

\section{Closed box with a dimmer and a fan (Scenario 5)}

For a more accurate model of the car, after adding the fan, the next test was adding a dimmer to the lamp, so there were two changes made in this test. While the dimmer reduced the heating capacity of the lamp, the fan would blow the wind flow around the car. It was expected that the temperature would get closer to the actual condition of the car.

Finally, the last scenario was done and the results are presented in Fig. 8a, which shows that there are differences compared to the temperatures under test conditions with a

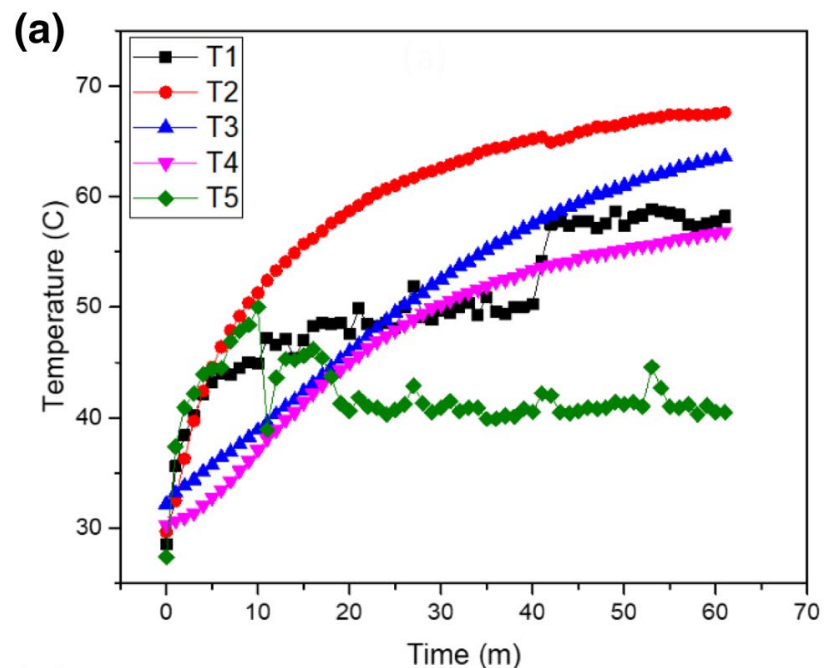

(b)

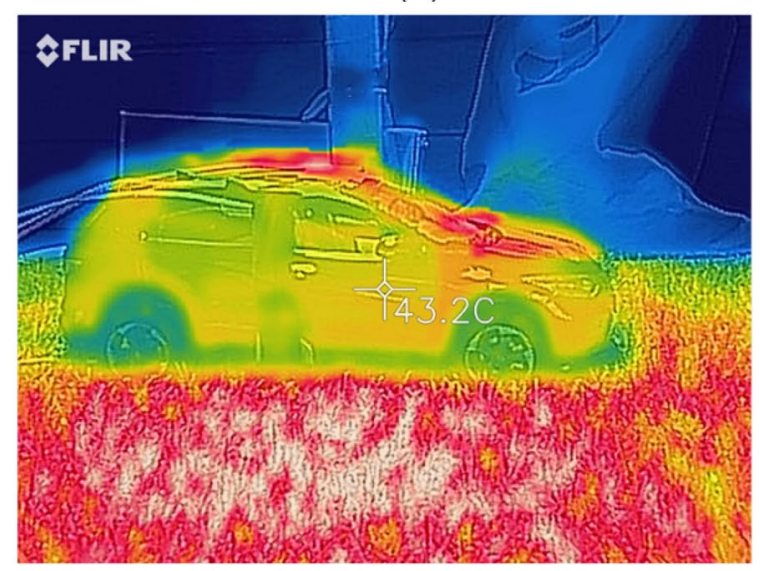

Fig. 5 Closed box (Scenario 2) a graphics of temperature rise in a model car, $\mathbf{b}$ heat distribution image of a model car

fan only and with a dimmer only. In these conditions, the temperature pattern obtained in the cabin (T2) was similar to that of the real car, i.e., only as high as $41^{\circ} \mathrm{s}$, and the ambient temperature was only $30^{\circ}$. This change shows a graph that is close to the real condition because of fluctuations in the external sensor as well as the ambient temperature (T2) that tended to be stable. Only the difference in T3 was still high, and the maximum value of the temperature difference was less than $15^{\circ}$.

Using Eq. (1), we could calculate the figure of merit of the TEG and we used:

$Z=\left[\frac{-228-185}{\sqrt{\sqrt{12.6 \times 1.8}-\sqrt{12.6 \times 1.3}}}\right]^{2}$ 


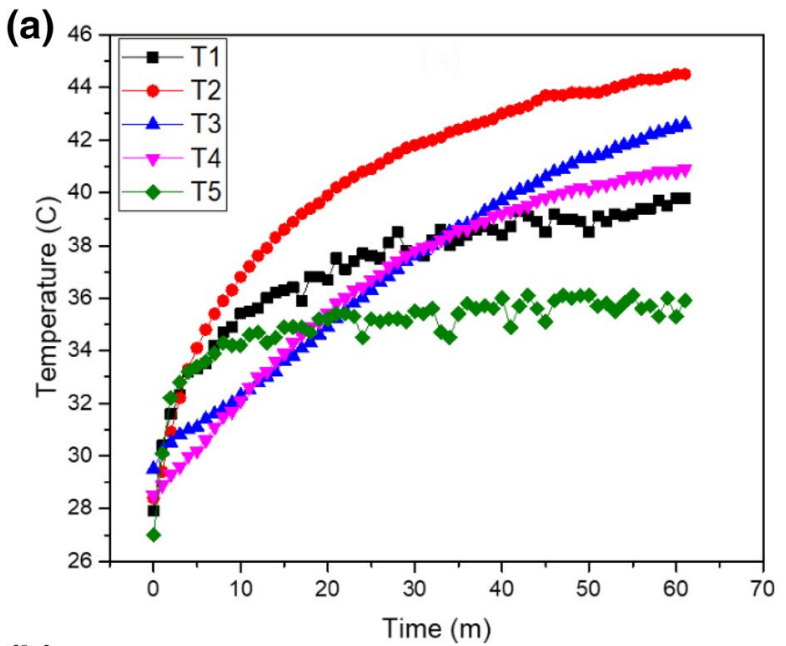

(b)

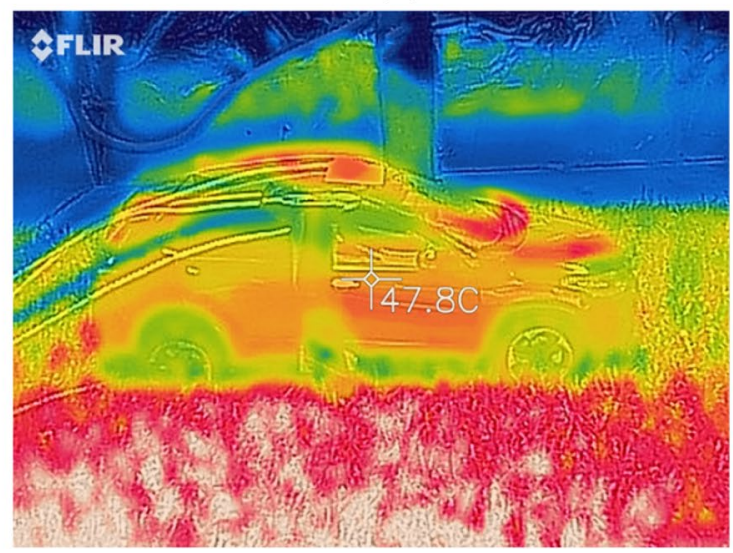

Fig. 6 Closed box equipped with a dimmer (Scenario 3) a graphic of temperature rise of a model car, $\mathbf{b}$ heat distribution image of a model car

$$
Z=2119 \mathrm{~K}^{-1} \text {. }
$$

As mentioned previously, the maximum $\Delta T$ of temperatures from the inside roof of the car refers to the difference between scenarios. Of all the existing scenarios, the one closest to the temperature graph inside the cabin roof is Scenario 4 , where the graphic form and the results resemble the actual car. Although for the maximum temperature that is most suitable is the second scenario, where the maximum temperature difference between the roof temperature and the ambient temperature resembles the actual car measurement results.

Then, taking the value of power and currents of the datasheet and Eq. (4), eTEG ${ }^{\mathrm{TM}}$ HV37 power generation can be calculated as follows:

$P=0.0086772 \Delta T^{2}+0.020226 \Delta T+0.01002$.

As observed, in the research and measurements above, it can be concluded that the highest amount of heat in a parked car collects inside the roof of the vehicle. This means that the temperature will rise drastically within $60 \mathrm{~min}$ of
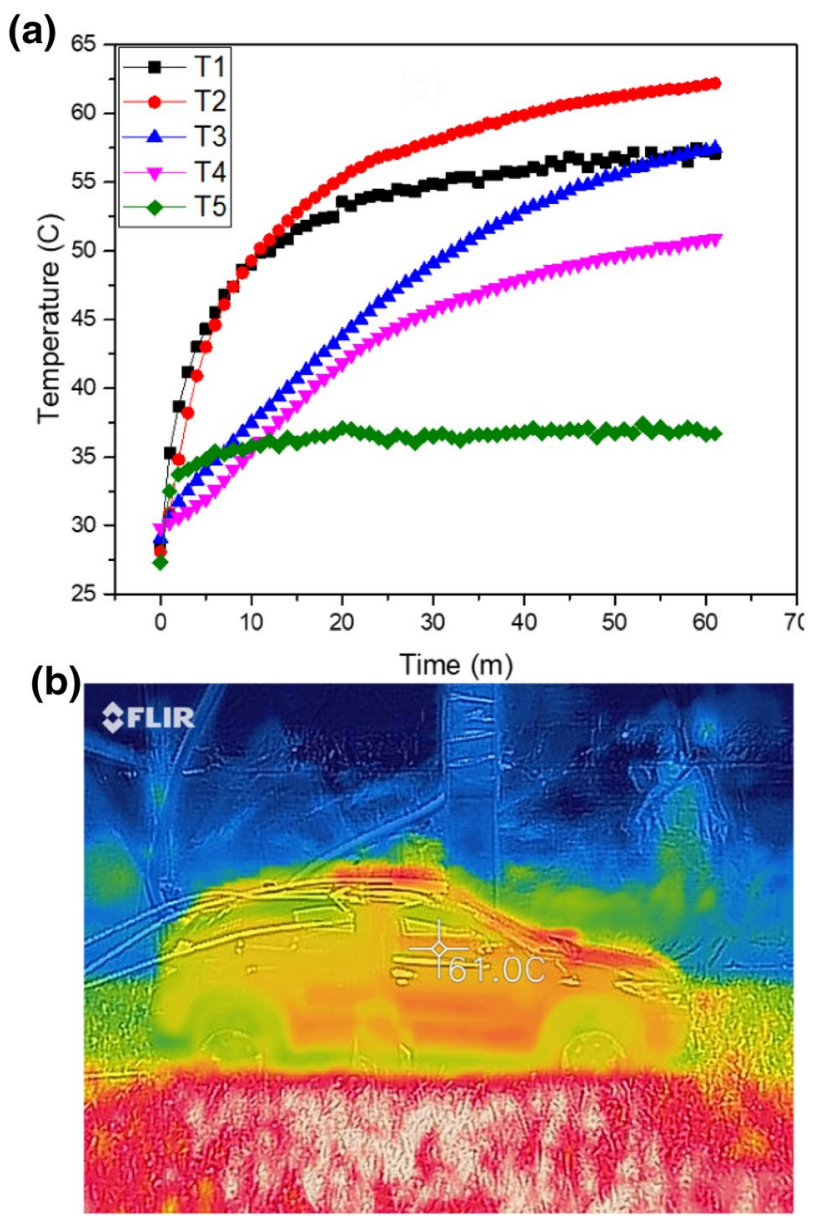

Fig. 7 Closed box equipped with a fan (Scenario 4) a graphic of temperature rise of a model car, $\mathbf{b}$ heat distribution image of a model car

measurement. The collected heat and the ambient temperature outside may vary by up to $25^{\circ}$, where such a temperature difference can potentially help the thermoelectric system to function normally.

According to the temperature difference between the roof $\mathrm{T} 2$ and the ambient temperature $\mathrm{T} 5$, and using the thermoelectric system eTEGTM HV37, we can obtain an estimation of output power, as shown in Fig. 9. This result indicates that power in the real car scenario and Scenario 2 could reach a maximum of $6.9 \mathrm{~mW}$, but it was not stable, because the ambient temperature also rose and reduced $\Delta \mathrm{T}$.

While the real car and Scenario 2 could produce a higher energy level, the other scenarios could also produce energy, but it was relatively small, i.e., a maximum of $3.5 \mathrm{~mW}$ and by $2 \mathrm{~mW}$ on average. It is well known that thermoelectrics need a substantial $\Delta T$ value to produce larger output.

The calculated power is from an estimation from a $2.1 \mathrm{~mm} \times 3.4 \mathrm{~mm}$-sized thermoelectric generator. If using the roof of the vehicle as a place to put the thermoelectric module, it can be assumed that the roof area used is taken 


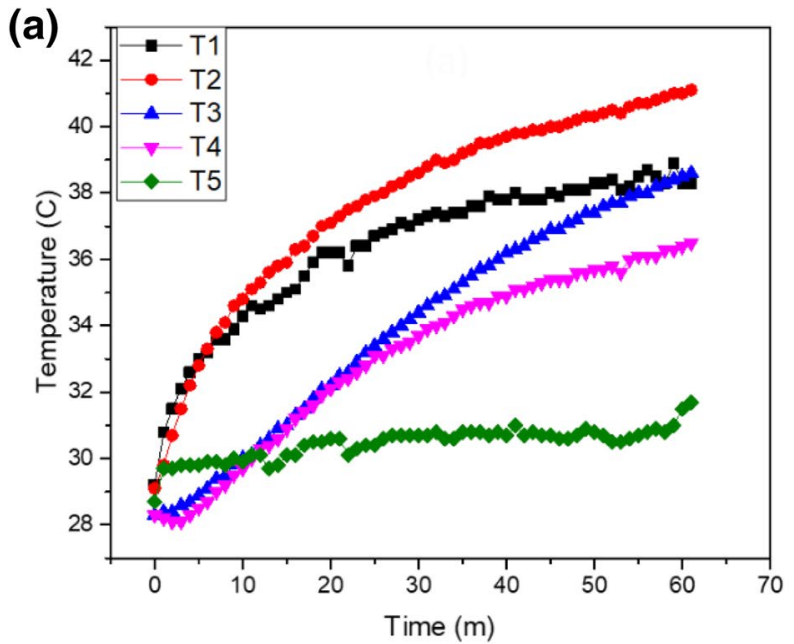

(b)

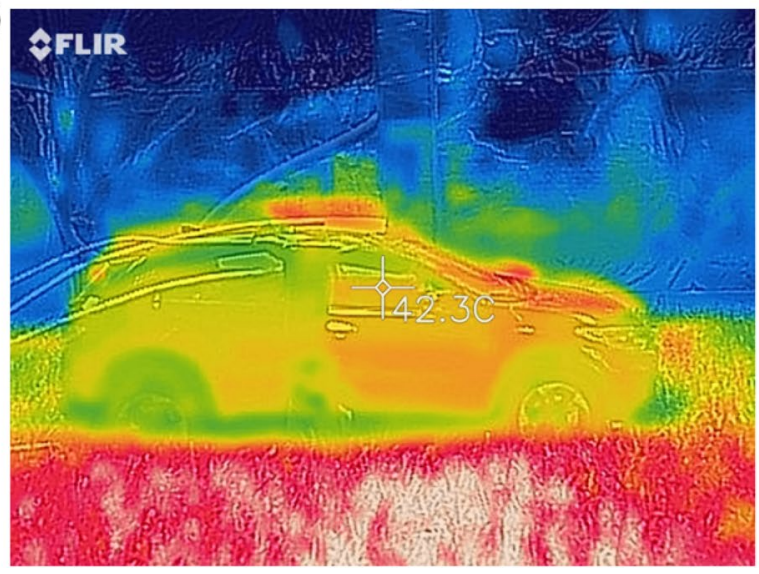

Fig. 8 Closed box equipped with a fan and a dimmer (Scenario 5) a graphic of temperature rise of a model car, $\mathbf{b}$ heat distribution image of a model car

about one square meter, meaning that $294 \times 476$ grid modules or as many as 139,944 modules can be installed. If one module can produce power by $2 \mathrm{~mW}$ on average, then with 139,944 modules, we can obtain up to $280 \mathrm{~W}$ of power.

\section{Conclusions}

The study on the car cabin heat pattern under a condition of sunlight exposure had been carried out experimentally and numerically. The experimental results have been obtained based on measurements conducted on a real car and a model car. The measurements were carried out under a condition of sunlight exposure and scenarios' set in an environment with exposure to the lamp.

Results for both the real car and the model car indicate that heat rose drastically inside the car cabin compared to the ambient temperature. The calculation using the thermoelectric generator eTEG HV37 considerably could generate up to $6 \mathrm{~mW}$ of power per module. Therefore, $280 \mathrm{~W}$ of power

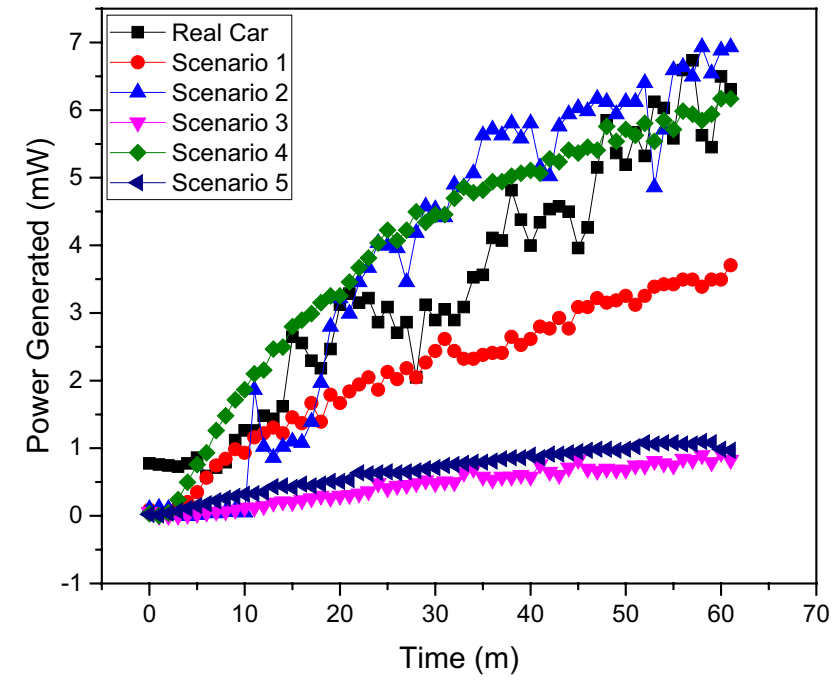

Fig. 9 Comparison of estimated output power generated by thermoelectric generator eTEG HV37 using difference in the temperature inside and outside the car as the heat source

could be produced by having a thermoelectric installed on an area of $1 \mathrm{~m}^{2}$ of the car roof.

Acknowledgements This work is supported by Hibah Tadok Universitas Indonesia 2018 funded by DRPM Universitas Indonesia No. 5000/ UN2.R3.1/HKP.05.00/2018.

Author contribution AS performed the experimental work including temperature measurement and data analysis. $\mathrm{CH}$ designed the overall work. AS, IG and $\mathrm{CH}$ were the main writers of the manuscript.

Open Access This article is distributed under the terms of the Creative Commons Attribution 4.0 International License (http://creativeco mmons.org/licenses/by/4.0/), which permits unrestricted use, distribution, and reproduction in any medium, provided you give appropriate credit to the original author(s) and the source, provide a link to the Creative Commons license, and indicate if changes were made.

\section{References}

1. Kolhe, M., Muneer, T., Adhikari, S.K.: Parked electric vehicle's cabin temperature management using photovoltaic powered ventilation. Energy Procedia 142, 343-349 (2017). (12/01/2017)

2. Alnaser, W.E., Lahimer, A.A., Alghoul, M.A., Sopian, K., Khrit, N.G., Sayigh, A.A.: The effect of solar reflective cover on soak air temperature and thermal comfort of car parked under the sun. E3S Web Conf 23, 08003 (2017)

3. Pan, H., et al.: A portable renewable solar energy-powered cooling system based on wireless power transfer for a vehicle cabin. Appl. Energy 195, 334-343 (2017)

4. Shams, S., Poon, K., Aljunaibi, A., Tariq, M., Salem, F., Ruta, D.: Solar powered air cooling for idle parked cars: Architecture and implementation. In: 2015 11th International Conference on Innovations in Information Technology (IIT), pp. 239-243 (2015)

5. Daly, S.: Automotive Air-conditioning and Climate Control Systems, pp. 1-61. Butterworth-Heinemann, Oxford (2006) 
6. Goldsmid, H.J.: Introduction to Thermoelectricity, pp. 7-21. Springer, Berlin (2009)

7. Attar, A., Lee, H.: Designing and testing the optimum design of automotive air-to-air thermoelectric air conditioner (TEAC) system. Energy Conv. Manag. 112, 328-336 (2016)

8. Choi, H.-S., Yun, S., Whang, K.-I.: Development of a temperature-controlled car-seat system utilizing thermoelectric device. Appl. Therm. Eng. 27(17-18), 2841-2849 (2007)

9. Weng, C.-C., Huang, M.-J.: A simulation study of automotive waste heat recovery using a thermoelectric power generator. Int. J. Therm. Sci. 71, 302-309 (2013)

10. Orr, B., Akbarzadeh, A., Mochizuki, M., Singh, R.: A review of car waste heat recovery systems utilising thermoelectric generators and heat pipes. Appl. Therm. Eng. 101, 490-495 (2016)

11. He, W., Wang, S., Yang, Y.: Peak power evaluation and optimal dimension design of exhaust heat exchanger for different gas parameters in automobile thermoelectric generator. Energy Convers. Manag. 151, 661-669 (2017)

12. Muralidhar, N., Himabindu, M., Ravikrishna, R.V.: Modeling of a hybrid electric heavy duty vehicle to assess energy recovery using a thermoelectric generator. Energy 148, 1046-1059 (2018)

13. Danca, P., Vartires, A., Dogeanu, A.: An overview of current methods for thermal comfort assessment in vehicle cabin. Energy Procedia 85, 162-169 (2016)

14. Singh, O.P., Raut, R., Biswas, M., Singh, R.: Effect of dynamic vents on the thermal comfort of a passenger car. Strojniški vestnik J. Mech. Eng. 61(11), 561-570 (2015)

15. Othoman, M.A., Fouzi, M.S.M., Nordin, A.: Assessment of thermal comfort in a car cabin under sun radiation exposure. Eng Appl New Mater Technol 85, 469-479 (2018)
16. Al-Kayiem, H.H., Sidik, M.F., Munusammy, Y.R.: Study on the thermal accumulation and distribution inside a parked car cabin. Am J Appl Sci 7(6), 784-789 (2010)

17. Guard, A., Gallagher, S.S.: Heat related deaths to young children in parked cars: an analysis of 171 fatalities in the United States, 1995-2002. Inj Prev 11(1), 33-37 (2005)

18. Horak, J., Schmerold, I., Wimmer, K., Schauberger, G.: Cabin air temperature of parked vehicles in summer conditions: life-threatening environment for children and pets calculated by a dynamic model. Theor Appl Climatol 130(1-2), 107-118 (2016)

19. Grundstein, A., Null, J., Meentemeyer, V.: Weather, geography, and vehicle-related hyperthermia in children. Geogr. Rev. 101(3), 353-370 (2011)

20. Kitsuya, T., Zang, W., Kumagai, S., Kishima, S.: Target for heat capacity consumption that considers safety, energy savings, and comfort: a room heat capacity model using a two-phase difference integration method. Int J Energy Environ Eng 8(1), 1-8 (2016)

21. Grundstein, A., Meentemeyer, V., Dowd, J.: Maximum vehicle cabin temperatures under different meteorological conditions. Int. J. Biometeorol. 53(3), 255-261 (2009)

Publisher's Note Springer Nature remains neutral with regard to jurisdictional claims in published maps and institutional affiliations. 